\title{
Structural, optical, and electrical properties of thioglycolic acid-capped CdTe quantum dots thin films
}

\author{
Rostam Moradian ${ }^{1,2,3^{*}}$, Mohammad Elahi' ${ }^{1}$ Ahmad Hadizadeh ${ }^{1}$, Mahmoud Roshani ${ }^{4}$, Atefeh Taghizadeh ${ }^{1}$ \\ and Reza Sahraei ${ }^{4}$
}

\begin{abstract}
Water-soluble cadmium telluride (CdTe) quantum dots (QDs) were synthesized using thioglycolic acid as capping agent; this reaction was carried out at $\mathrm{pH}=10.2$ and refluxed at $100^{\circ} \mathrm{C}$ for $18 \mathrm{~h}$. The $\mathrm{CdTe}$ QDs prepared at various reflux times from 1 to $18 \mathrm{~h}$ were coated on the glass substrates to obtain thin films of the CdTe QDs with the same thickness. The CdTe thin films were characterized by X-ray diffraction, ultraviolet-vis spectroscopy, and photoluminescence spectroscopy. The absorption thresholds of the CdTe thin films are blueshifted by about $0.65 \mathrm{eV}$ with respect to the bulk value $(1.5 \mathrm{eV})$, due to the quantum size effect as expected from the nanocrystalline nature of the CdTe QDs. X-ray diffraction showed that the films consisted of small CdTe nanocrystallites, 2.91 to $3.57 \mathrm{~nm}$ in size, showing quantum size effects. The effects of temperature on the electrical properties of the films were studied in detail. Electrical resistivity measurements were carried out for different films in the temperature range from 343 to $463 \mathrm{~K}$. It is shown that activation energy increases by increasing the reflux time.
\end{abstract}

Keywords: CdTe quantum dots; Thin films; Optical properties; Electrical conductivity

\section{Background}

Colloidal semiconductor quantum dots (QDs) are promising candidate materials for realizing photovoltaics and optoelectronic devices. They can be fabricated near room temperature and scalable to large-area substrates [1-3]. Various artificially nanostructured materials have also become available which possess large transition dipole moments and consequently strong optical absorption [4]. Being coated on any surface and capability of the band gap to be tuned by changing the size and the shape of the particle are the potential advantages of colloidal QDs [5,6]. Among these artificial nanostructures, of the most interest are colloidal synthesized QD semiconductors which can be processed from solution due to the broad optical response that can be tuned from visible to infrared by the selection of the type and physical size of the nanocrystals [7-9]. The CdTe QD semiconductors have a direct band gap that can be tuned

\footnotetext{
* Correspondence: moradian.rostam@gmail.com

'Department of Physics, Razi University, Kermanshah, Iran

${ }^{2}$ Nano Science and Nano Technology Research Center, Razi University, Kermanshah, Iran

Full list of author information is available at the end of the article
}

from 1.5 to $2.1 \mathrm{eV}$, covering most of the range of the peak emission power of the solar spectrum, and hence, they are suitable materials for photovoltaic applications [10-13]. They are also beneficial for thermoelectric applications, as they have the lowest possible thermal conductivity [14].

Carrier transport in the QD thin films can manifest both hopping transport and conduction band transport features. The hopping transport regime is characterized by its dependence on different temperatures and much lower mobility values than the band conduction transport. What causes the transport regime prevail depends on the structural and morphological properties of the QD thin films. Despite its importance for practical applications, there has been relatively little work done on charge transport in the QD thin films [1]. Experimental investigation of thermal transport in such structures has also just begun [14]. For thermoelectric applications, it is important to measure both electrical and thermal conductivities in the same set of QD thin film samples.

In this paper, a monodisperse size series of thioglycolic acid-stabilized CdTe QDs with extremely small sizes was synthesized by a wet chemical route in aqueous solutions at various reflux times and coated on glass substrate for

\section{实}


the formation of CdTe QD thin films. The synthesis allows obtaining a size series of highly luminescent CdTe QDs with emission colors covering the visible spectral range from green to red. Furthermore, the deposited thin films are also characterized in terms of optical, electrical, and nanocrystalline structural properties in details. Although several groups have performed the deposition of nanocrystalline CdTe thin films by different methods, there are only few reports discussing the electrical properties of CdTe QD thin films at different temperature ranges [15-18].

\section{Methods}

\section{Materials and apparatus}

Cadmium sulfate octahydrate $\left(\mathrm{CdSO}_{4} \cdot 8 \mathrm{H}_{2} \mathrm{O}\right)$, tellurium (Te) powder, sodium borohydride $\left(\mathrm{NaBH}_{4}\right)$, sodium hydroxide $(\mathrm{NaOH})$, and thioglycolic acid $\left(\mathrm{HSCH}_{2} \mathrm{CO}_{2} \mathrm{H}\right)$ were of analytical grade and were not further purified before use. An Agilent 7200 UV-vis spectrophotometer was used to record the absorption spectra in the wavelength range of 300 to $800 \mathrm{~nm}$ at room temperature. $\mathrm{X}$-ray diffraction (XRD) patterns were recorded in the thin film grazing angle mode with an automated Philips X'Pert X-ray diffractometer (Koninklijke Philips N.V., Amsterdam) with $\mathrm{CuK} \alpha$ radiation $(40 \mathrm{kV}$ and $30 \mathrm{~mA})$ for $2 \theta$ values over $10^{\circ}$ to $80^{\circ}$. Photoluminescence (PL) measurements were performed at room temperature using a Cary Eclipse spectrofluorometer (Agilent Technologies Inc., Santa Clara, CA, USA) equipped with a $20-\mathrm{kW}$ xenon discharge lamp as a light source. The excitation wavelength of photoluminescence was fixed at $390 \mathrm{~nm}$. The thin film thickness was measured using an AlphaStep 500 profiler (KLA-Tencor Corp., Milpitas, CA, USA). The two-point probe method was employed to measure the electrical resistivity as a function of temperature in the range of working temperature between $343 \mathrm{~K}$ and $463 \mathrm{~K}$. Using appropriate mask and evaporation of gold, ohmic contact was made on the thin films. The copper constantan thermocouple was employed to measure the temperature, and the voltage of the samples was controlled by a Keithley electrometer (Model 6517A, Keithley Instruments Inc., Cleveland, OH, USA).

\section{Preparation of $\mathrm{CdTe}$ quantum dots}

In a 50-mL two-neck flask, $278.8 \mathrm{mg} \mathrm{NaBH}_{4}$ and $7 \mathrm{~mL}$ double distilled water were deaerated with argon and stirred for $30 \mathrm{~min}$. Then, $90 \mathrm{mg}$ tellurium powder was added, and the resulting suspension was stirred under argon until tellurium powder was completely dissolved. After that, the resulting suspension was cooled down to $0^{\circ} \mathrm{C}$ under vigorous stirring and argon bubbling. During $15 \mathrm{~min}$, the characteristic color of the suspension changed from faint pink to colorless state. The disappearance of the solution color is due to the formation of aqueous sodium hydrogen telluride (NaHTe) solution. After removal by filtration, the obtained solution transferred into the two-neck flask and $42 \mathrm{~mL}$ of double distilled water was added, deaerated with argon, and stirred for 120 min. Finally, the prepared NaHTe solution was kept at $5^{\circ} \mathrm{C}$ and was used freshly in the next experiments.

The CdTe QDs were prepared using the reaction between the $\mathrm{Cd}^{2+}$ and NaHTe solutions following the modified method described elsewhere [12]. In a three-neck flask $(250 \mathrm{~mL})$ equipped with flux condenser, $294.6 \mathrm{mg}$ of $\mathrm{CdSO}_{4} \cdot 8 \mathrm{H}_{2} \mathrm{O}$ was dissolved in $176 \mathrm{~mL}$ double distilled water. After the addition of $200 \mu \mathrm{L}$ thioglycolic acid (TGA), the solution was adjusted to $\mathrm{pH} 10.2$ with aqueous $\mathrm{NaOH}$ solution $(1.0 \mathrm{M})$ and stirred under argon atmosphere at room temperature for $30 \mathrm{~min}$. Then, freshly prepared NaHTe solution was injected under argon atmosphere, and the mixture was refluxed. The color of the precursor's mixture turned from colorless to orange, clearly supporting the nucleation and growth of the TGA-stabilized CdTe nanocrystals. The resulting solution was refluxed under nitrogen atmosphere at different times and at constant temperature of $100^{\circ} \mathrm{C}$ to produce the TGA-stabilized CdTe QDs.

\section{Preparation of thin films}

Commercial microscope slide glass substrates $(16 \times 25 \times$ $1 \mathrm{~mm}$ ) were used as the substrate. The glass substrates were first ultrasonically cleaned in sulfochromic acid solution, washed with deionized water, isopropyl alcohol, and doubly distilled water, respectively, and dried in an oven at $90^{\circ} \mathrm{C}$ for about $1 \mathrm{~h}$. The thin films of CdTe QDs were spin coated on glass substrates at $4,000 \mathrm{rpm}$ for $60 \mathrm{~s}$. Then, the glass substrates coated with CdTe QDs are placed in a vacuum environment (approximately $10^{-3}$ Torr) for approximately $1 \mathrm{~h}$ to evaporate the solvent.

\section{Results and discussion}

\section{Characterization of CdTe thin films}

Figure 1 shows the UV-vis absorption spectra of the CdTe QDs coated onto the glass substrates as a function of reflux time. The film thickness of the CdTe QDs coated on the glass substrates was about $130 \mathrm{~nm}$. The measurement of the absorption spectra was carried out at various reflux times and extended to longer reflux times than $18 \mathrm{~h}$ to reveal the effect of reflux time on the optical, structural, and electrical characterization of the CdTe thin films. As shown in Figure 1, the presence of typical excitonic peak and redshifts from 520 to $575 \mathrm{~nm}$ with the CdTe precursor undergoing a continuous refluxing process which attributed to $1 s$ to $1 s$ electronic transition of the nanoparticles indicates that the size of $\mathrm{CdTe}$ QDs gradually increased [19]. The redshift of the absorption peaks in Figure 1 clearly demonstrates the growth of the nanocrystals and formation of the CdTe QDs with various sizes at different reflux times. It also confirms by the change of the CdTe thin films' color 


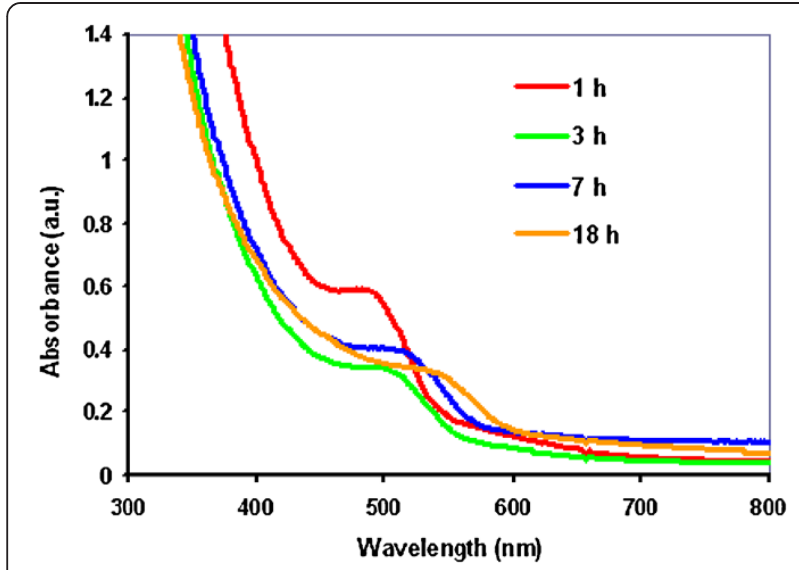

Figure 1 Optical absorption spectra of thin films of the CdTe QDs synthesized at various reflux times: 1, 3, 7, and $18 \mathrm{~h}$.

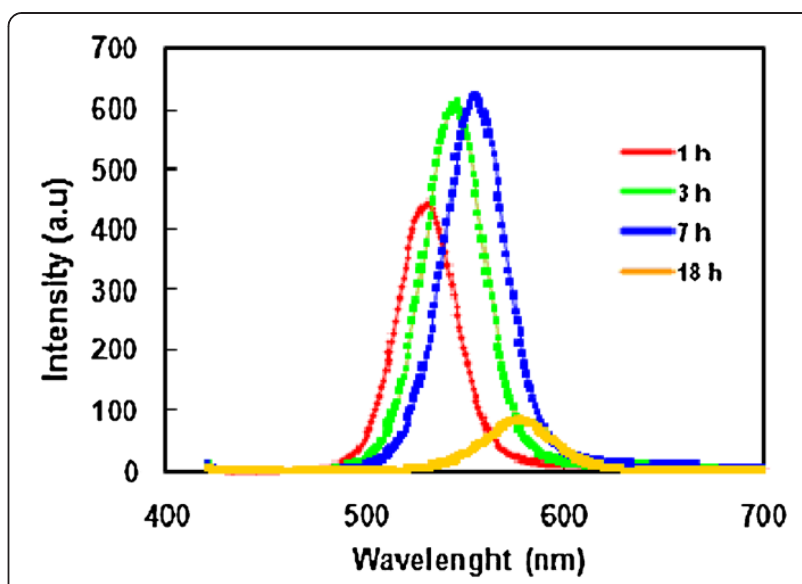

Figure 2 PL spectra of thin films of the CdTe QDs synthesized at different reflux times: $1,3,7$, and $18 \mathrm{~h}$. from transparent light yellow at initial reflux time to orange after $18 \mathrm{~h}$. This is an effect of the Ostwald ripening mechanism as smaller particles dissolve in the process of producing larger particles [20,21]. The relative sharpness of the absorption edges is attributed to the formation of the CdTe QDs with a narrow size distribution. So, there is a blueshift of at least $230 \mathrm{~nm}, 0.65 \mathrm{eV}$ in energy, in comparison with that of the bulk CdTe at $810 \mathrm{~nm}$ $(1.5 \mathrm{eV})$. This blueshift in the absorption edges is most probably due to the quantum size effect as expected from the nanosized nature of the CdTe QDs [22,23].

According to the literature survey, the particle size of CdTe QDs is estimated using the following empirical fitting expression [24]:

$$
\begin{aligned}
D= & \left(9.8127 \times 10^{-7}\right) \lambda^{3}-\left(1.7147 \times 10^{-3}\right) \lambda^{2} \\
& +(1.0064) \lambda-194.84 .
\end{aligned}
$$

In the above function, $D(\mathrm{~nm})$ is the size of a given CdTe QD, and $\lambda(\mathrm{nm})$ is the wavelength of the first excitonic absorption peak of the corresponding CdTe QDs. Our results show that the particle sizes of the prepared CdTe QDs are 2.81, 3.01, 3.24, and $3.47 \mathrm{~nm}$, corresponding to the first excitonic absorption peaks of 520, 530, 550, and $575 \mathrm{~nm}$ for the CdTe QDs obtained at different reflux times.

The PL emission spectra of the CdTe thin films were performed to investigate the optical variation of the $\mathrm{CdTe}$ QDs during their growth at different reflux times from 1 to $18 \mathrm{~h}$. As shown in Figure 2, the PL spectra are dominated by single large peaks centered in $532,545,557$, and $578 \mathrm{~nm}$, corresponding to the reflux times of $1,3,7$, and $18 \mathrm{~h}$, respectively. The PL bands (Figure 2) are located close to the absorption thresholds (so called band edge) and are sufficiently narrow (full width at half maximum, as low as $45 \mathrm{~nm}$ being increased up to 65 to $70 \mathrm{~nm}$ for size fractions of large CdTe QDs).

Figure 3 shows the XRD patterns obtained from thin films of the CdTe QDs synthesized at different reflux times. The standard XRD pattern for CdTe (Joint Committee for Powder Diffraction Standards, JCPDS card No. 10-0207) is given at the bottom of Figure 3. The thin films are all polycrystalline with random crystal orientation and show no signs of texturing. The three broad peaks observed in the diffractogram at around $23.8^{\circ}, 44.3^{\circ}$, and $52.2^{\circ}$ reveal a cubic lattice structure of $\mathrm{CdTe}$ (zinc blende). These peaks could be readily assigned to the planes (111), (200), and (311), respectively, of the cubic phase [25]. From the full width at half maximum of the (111) diffraction peaks, the average sizes of the CdTe QDs have been calculated using

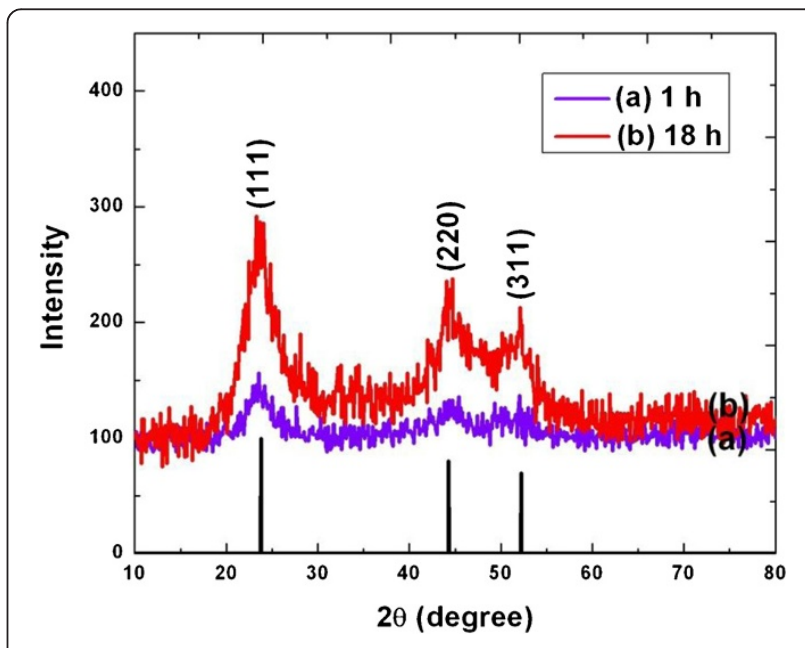

Figure 3 XRD patterns of thin films of the CdTe QDs synthesized at different reflux times. (a) 1 and (b) $18 \mathrm{~h}$. 
the Debye-Scherrer equation [26], and the results are shown in Table 1.

\section{Electrical properties}

Electrical conductivity is a prominent factor revealing information about the transport phenomenon. Recent works on electrical properties of nanocrystalline semiconductors have paid considerable attention toward the conduction mechanism [27]. In nanocrystalline materials due to the small size of grain and large grain boundaries, the electronic states close to Fermi levels are localized. When the states are localized, the conduction occurs by hopping of carriers between occupied and unoccupied localization which depends on the density of the state and the position of the Fermi level. Ichimura et al. established a dependence of conductivity with temperature for such systems [28]. The electrical conductivity of the CdTe QD thin films was carried out in the temperature range of 343 to $463 \mathrm{~K}$ at different reflux times of $1,3,7$, and $18 \mathrm{~h}$. The conductivity measurement shows that the thin films have an electrical resistivity order of $10^{6} \Omega \cdot \mathrm{cm}$ at room temperature. The high resistivity of the thin films may be due to the high grain boundary density, discontinuities, and small grain size of the CdTe QDs [29].

The glass substrate was heated by a specially designed heater, and the temperature was measured by a cupperconstantan thermocouple placed on the surface of the substrate. The conductivity was obtained by applying a DC voltage bias across the film with a gold electrode, and the current and voltage were simultaneously recorded using a standard two-point probe method. The activation energy $\left(E_{\mathrm{a}}\right)$ was determined using the following equation [30]:

$$
\sigma=\sigma_{0} \exp \left(-E_{\mathrm{a}} / k T\right)
$$

where $\sigma$ is the resistivity at temperature $T, \sigma_{0}$ is a constant, $k$ is the Boltzman constant, and $T$ is the absolute temperature. The activation energies were calculated from the local gradients of the $\ln \sigma$ versus the inverse temperature plots.

The plot of $\ln \sigma$ versus $1,000 / T$ for the different films was shown in Figure 4. It is interesting to note that conductivity appears to vary continuously with inverse temperature,

Table 1 QD size and activation energy values for thin films of CdTe QDs synthesized at different reflux times

\begin{tabular}{lcccc}
\hline \multirow{2}{*}{$\begin{array}{l}\text { Reflux time } \\
\text { (h) }\end{array}$} & $\begin{array}{c}\text { QD size } \\
\text { (nm) }\end{array}$ & \multicolumn{3}{c}{$\begin{array}{c}\text { Activation energies, } E_{\mathrm{a}}(\mathrm{eV}) \text {, } \\
\text { at different temperature ranges (K) }\end{array}$} \\
\cline { 3 - 5 } & $\mathbf{3 4 3}$ to $\mathbf{3 6 3 \mathrm { K }}$ & $\mathbf{3 7 3}$ to $\mathbf{4 0 3 ~ K}$ & $\mathbf{4 1 3}$ to $\mathbf{4 6 3 ~ K}$ \\
\hline 1 & 2.91 & 0.00973 & 0.10722 & 0.45801 \\
3 & 3.05 & 0.01246 & 0.11025 & 0.49024 \\
7 & 3.32 & 0.01781 & 0.14591 & 0.52991 \\
18 & 3.57 & 0.03038 & 0.19109 & 0.83484 \\
\hline
\end{tabular}

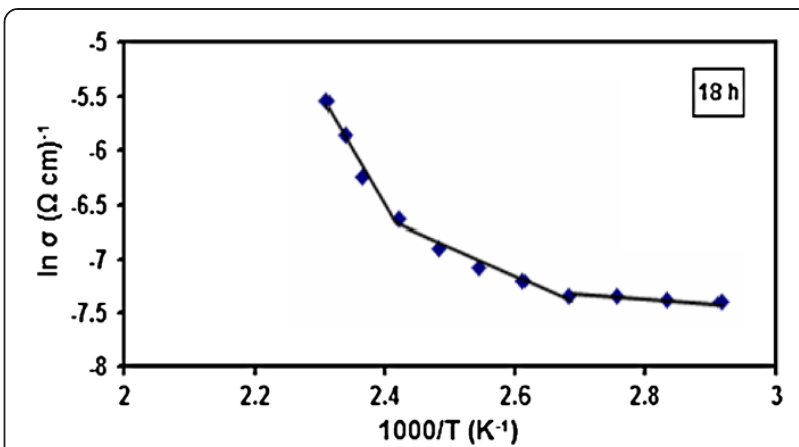

Figure 4 Ino-versus-1,000/T plot of thin film of CdTe QDs synthesized at 18 -h reflux time.

and the variation of their slopes suggests a thermally activated conduction mechanism. The conductivity of these samples cannot be represented by a single exponential but can be fitted by a smoothed curve with gradually increasing slope, providing a spectrum of activation energies. Therefore, the whole temperature region was divided into three temperature ranges: (1) high temperature range (413 to $463 \mathrm{~K}$ ), (2) intermediate temperature range (373 to $412 \mathrm{~K}$ ), and (3) low temperature range ( 343 to $372 \mathrm{~K}$ ). It must be considered that at temperature less than $343 \mathrm{~K}$, all the samples show similar behaviors (Figure 4). The activation energies for the four different CdTe thin films including QDs with grain sizes of 2.91, 3.05, 3.32, and $3.57 \mathrm{~nm}$ were obtained (Table 1). It was observed that the increase in the reflux time leads to an increase in the amount of thin film activation energy. Moreover, it is clear from Table 1 that as temperature increases, the activation energy increases for all the investigated films. Therefore, it can be assumed that at higher temperatures, the carriers are activated to the localized states, and the conductivity moves away from the states near the Fermi level. The gradual increase in the activation energy may suggest the probability of several impurity levels in the band gap.

The grain size dependence of the activation energy is due to the grain boundary barrier effect and large dislocation density [31]. Our results show that increasing the reflux time, which in itself leads to the increasing size of the CdTe QDs, increases the activation energy in a way that the largest one is observed within the time span of $18 \mathrm{~h}$. The point to notice with this regard is the fact that although the size of the CdTe QDs will increase in commensurate with the increase in the reflux time, the considerable impact regarding the increase in the activation energy is widening the distance between the CdTe QD grains which have out formed as thin films.

According to Table 1, it is clear that the activation energy at the three different branches is a function of the reflux time. This behavior could be attributed to the grain size dependence of the activation energy [31]. 


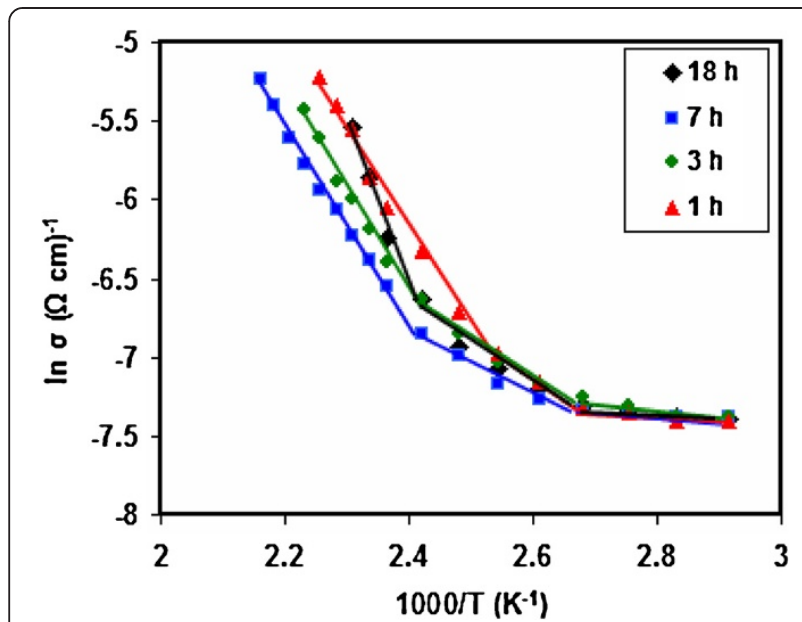

Figure 5 In $\sigma$-versus-1,000/T plots of thin films of CdTe QDs synthesized at various refluxing times: $1,3,7$, and $18 \mathrm{~h}$.

It is interesting that the CdTe QD thin film synthesized at reflux time of $18 \mathrm{~h}$ shows the semiconducting features earlier than the other thin films (Figure 5). Although the CdTe QD thin film synthesized at the reflux time of $18 \mathrm{~h}$ has a greater $E_{\mathrm{a}}$, it shows a better thermally conduction mechanism at lower temperature than the other thin films. Therefore, the sample synthesized at the reflux time of $18 \mathrm{~h}$ is a good semiconductor to use in semiconducting devices. The main reason for this can be attributed to the increase in the distance between grain boundaries and the size of quantum dots simultaneously.

\section{Conclusion}

In this study, tunable CdTe QD thin films were prepared using a simple aqueous method with TGA as the capping agent at $100^{\circ} \mathrm{C}$ and at different reflux times. A photoluminescence peak with full width at half maximum of around 45 to $70 \mathrm{~nm}$ indicating a homogeneous and narrow size distribution of the CdTe QD thin films and structural measurements through XRD analysis demonstrated that the CdTe thin films have a cubic structure. The electrical properties of the CdTe thin films were presented, and it was found that the temperature increase will increase the activation energy but will decrease the thin film's electronic thermal conductivity. It was also shown that the electrical conductivity in the higher temperature is due to the hopping of the carriers between localized states at the Fermi levels. Moreover, the results obtained in this study showed that the increase in the thin film activation energy depends not only on the reflux time but also on the distance between the grain boundaries of quantum dots in the thin films.

\section{Competing interests}

The authors declare that they have no competing interests.

\section{Authors' contributions}

$H, A T, M R$ carried out the experiments, analyzed the data and participated in the manuscript preparation. RM as the corresponding author participated throughout the investigations and manuscript writing. Other read and approved the final manuscript.

\section{Authors' information}

Rostam Moradian: full Prof. of condensed matter physics - Department of Physics, Razi University, Kermanshah, Iran.

Mohhamad Elahi: Assosiated Prof. of condensed matter physics Department of Physics, Razi University, Kermanshah, Iran.

Ahmad Hadizadeh: Phd student of condensed matter physics - Department of Physics, Razi University, Kermanshah, Iran.

Mahmoud Roushani: Assistant Prof. of chemistry Department of Chemistry, Ilam University, Ilam, Iran.

Atefeh Taghizadeh: Master of degree of condensed matter physics. Reza Sahraeid: Assistant Prof. of chemistry Department of Chemistry, Ilam University, Ilam, Iran.

\section{Acknowledgements}

The authors would like to acknowledge the Mrs. Atefeh Ghaderi for her guidance.

\section{Author details}

${ }^{1}$ Department of Physics, Razi University, Kermanshah, Iran. ${ }^{2}$ Nano Science and Nano Technology Research Center, Razi University, Kermanshah, Iran. ${ }^{3}$ Computational Physical Science Research Laboratory, Department of Nano-Science, Institute for Studies in Theoretical Physics and Mathematics (IPM), P.O. Box 19395-5531, Tehran, Iran. ${ }^{4}$ Department of Chemistry, Ilam University, Ilam, Iran.

Received: 29 May 2013 Accepted: 17 September 2013

Published: 14 Nov 2013

\section{References}

1. Geyer, S, Porter, VJ, Halpert, JE, Mentzel, TS, Kastner, MA, Bawendi, MG Charge transport in mixed CdSe and CdTe colloidal nanocrystal films. Phys. Rev. B 82, 155201 (2010)

2. Mane, RK, Ajalkar, BD, Bhosale, PN: Opto-structural and electrical properties of chemically grown Ga doped MoBi2Se5 thin films. Mater. Chem. Phys. 84, 247-250 (2004)

3. Levy-Clement, C, Tena-Zaera, R, Ryan, MA, Katty, A, Hodes, G: CdSeSensitized p-CuSCN/Nanowire n-ZnO Heterojunctions. Adv. Mater. 17, 1512-1515 (2005)

4. Osedach, TP, Geyer, SM, Ho, JC, Arango, AC, Bawendi, MG, Bulović, V: Lateral heterojunction photodetector consisting of molecular organic and colloidal quantum dot thin films. Appl. Phys. Lett. 94, 043307 (2009)

5. Peng, ZA, Peng, X: Formation of High-Quality CdTe, CdSe, and CdS Nanocrystals Using CdO as Precursor. J. Am. Chem. Soc. 123, 183-184 (2001)

6. Yin, YD, Alivisatos, AP: Colloidal nanocrystal synthesis and the organic-inorganic interface. Nature 437, 664-670 (2005)

7. Steckel, JS, Coe-Sullivan, S, Bulović, V, Bawendi, MG: $1.3 \mu \mathrm{m}$ to $1.55 \mu \mathrm{m}$ Tunable Electroluminescence from PbSe Quantum Dots Embedded within an Organic Device. Adv. Mater. 15, 1862-1866 (2003)

8. Burda, C, Chen, XB, Narayanan, R, El-Sayed, MA: Chemistry and properties of Nanocrystals of Different Shapes. Chem. Rev. 105, 1025-1102 (2005)

9. Norris, DJ, Bawendi, MG: Measurement and assignment of the sizedependent optical spectrum in CdSe quantum dots. Phys. Rev. B 53 16338 (1996)

10. Gur, I, Fromer, NA, Geier, ML, Alivisatos, AP: Air-stable all-inorganic nanocrystal solar cells processed from solution. Science 310, 462-465 (2005)

11. Morales-Acevedo, A: Analytical model for the photocurrent of solar cells based on graded band-gap CdZnTe thin films. Sol. Energy Mater. Sol. Cells 90, 2213-2220 (2006)

12. Gaponik, N, Talapin, DV, Rogach, AL, Hoppe, K, Shevchenko, EV, Kornowski, A, Eychmuller, A, Weller, H: Thiol-Capping of CdTe Nanocrystals: An Alternative to Organometallic Synthetic Routes. J. Phys. Chem. B 106, 7177-7185 (2002) 
13. Kapitonov, AM, Stupak, AP, Gaponenko, SV, Petrov, EP, Rogach, AL, Eychmuller, A: Luminescence Properties of Thiol-Stabilized CdTe Nanocrystals. J. Phys. Chem. B 103, 10109-10113 (1999)

14. Bao, Y, Liu, WL, Shamsa, M, Alim, K, Balandin, AA, Liu, JL: Electrical and Thermal Conductivity of Ge/Si Quantum Dot Superlattices Semiconductor Devices, Materials, and Processing. J. Electrochem. Soc. 152, 432-435 (2005)

15. Sharma, K, Al-Kabbi, AS, Saini, GSS, Tripathi, SK: Electrical conduction mechanism in nanocrystalline CdTe (nc-CdTe) thin films. Appl. Phys. A 108 , 911-920 (2012)

16. Gao, M, Lesser, C, Kirstein, S, Mohwald, H: Electroluminescence of different colors from polycation/CdTe nanocrystal self-assembled films. J. Appl. Phys. 87, 2297-2302 (2000)

17. Mandal, SK, Chaudhuri, S, Pal, AK: Nanocrystalline CdTe films deposited by high-pressure sputtering: carrier transport at low temperature. Thin Solid Films 357, 102-110 (1999)

18. Al-Ghamdia, AA, Abd El-sadek, MS, Nagata, AT, El-Tantawy, F: synthesis, electrical properties and transport mechanisms of thermally vacuum evaporated CdTe nanocrystalline thin films. Solid State Commun. 152, 1644-1649 (2012)

19. Eychmüller, A, Rogach, AL: Chemistry and photophysics of thiol-stabilized II-VI semiconductor nanocrystals. Pure Appl. Chem. 72, 179-188 (2000)

20. Jun, YW, Choi, JS, Cheon, J: Shape control of semiconductor and metal oxide nanocrystal through nonhydrolyc colloidal routes. Angew. Chem. Int. Ed. 45, 3414-3439 (2006)

21. Sahraei, R, Mihandoost, A, Nabiyouni, G, Daneshfar, A, Roushani, M, Majles Ara, $\mathrm{MH}$ : Room temperature synthesis and characterization of ultralong $\mathrm{Cd}$ $(\mathrm{OH}) 2$ nanowires: a simple and template-free chemical route. Appl. Phys. A 109, 471-475 (2012)

22. Zhang, H, Wang, L, Xiong, H, Hu, L, Yang, B, Li, W: Hydrothermal ynthesis for High-Quality CdTe Nanocrystals. Adv. Mater. 15, 1712-1715 (2003)

23. Scholes, GD: Controlling the optical properties of inorganic nanoparticles. Adv. Funct. Mater. 18, 1157-1172 (2008)

24. $\mathrm{Yu}, \mathrm{W}, \mathrm{Qu}, \mathrm{L}, \mathrm{Guo}, \mathrm{W}$, Peng, X: Experimental determination of the extinction coefficient of CdTe, CdSe, and CdS nanocrystals. Chem. Mater. 15, 2854-2860 (2003)

25. Ghaedi, M, Hekmati Jah, A, Khodadoust, S, Sahraei, R, Daneshfar, A, Mihandoost, A, Purkait, MK: Cadmium telluride nanoparticles loaded on activated carbon as adsorbent for removal of sunset yellow. Spectrochim. Acta, Part A 90, 22-27 (2012)

26. Goudarzi, A, Motedayen Aval, G, Sahraei, R, Ahmadpoor, H: Ammonia-free chemical bath deposition of nanocrystalline ZnS thin film buffer layer for solar cells. Thin Solid Films 516, 4953-4957 (2008)

27. Rakhesh, K, Joshi, H, Sehgal, K: Density of states near Fermi level in PbS nanoparticle films. Physica E 23, 168-170 (2004)

28. Ichimura, M, Gota, F, Arai, E: Structural and optical characterization of CdS films grown by photochemical deposition. J. Appl. Phys. 85, 7411-7417 (1999)

29. Kale, RB, Lokhande, CD: Influence of air annealing on the structural, optical and electrical properties of chemically deposited CdSe nano-crystallites. Appl. Surf. Sci. 223, 343-351 (2004)

30. Khemiri, N, Chaffar Akkari, F, Kanzari, M, Rezig, B: Studies of structural and optical properties of Cu-In-O thin films. Phys. Stat. Sol. A 205, 1952-1956 (2008)

31. Das, VD, Ganesan, PG: Electrical conduction studies on $\left(\mathrm{Bi}_{0.6} \mathrm{Sb}_{0.4}\right)_{2} \mathrm{Te}_{3}$ thin films. Semicond. Sci. Technol. 12, 195-202 (1997)

\subsection{6/2228-5326-3-56}

Cite this article as: Moradian et al: Structural, optical, and electrical properties of thioglycolic acid-capped CdTe quantum dots thin films. International Nano Letters 2013, 3:56

\section{Submit your manuscript to a SpringerOpen ${ }^{\circ}$ journal and benefit from:}

- Convenient online submission

- Rigorous peer review

- Immediate publication on acceptance

- Open access: articles freely available online

- High visibility within the field

- Retaining the copyright to your article

Submit your next manuscript at $\gg$ springeropen.com 